\title{
The experience of being a peer outreach volunteer: Benefits and challenges Robert King, ${ }^{1}$ Chris Lloyd, ${ }^{2}$ Alexis Clune ${ }^{3}$ and Rowena Allan ${ }^{3}$
}

\author{
1. Department of Psychiatry, The University of Queensland, St Lucia, Queensland, Australia \\ 2. Queensland Centre for Mental Health Research and the School of Population Health, The University of \\ Queensland, Brisbane, Queensland, Australia \\ 3. Department of Rehabilitation Sciences, The University of Queensland, St Lucia, Queensland, Australia
}

\begin{abstract}
Peer outreach is an emerging form of non-professional consumer-delivered service in the context of psychiatric rehabilitation. This study identified the benefits and challenges of outreach provision as identified by a group of volunteer outreach workers. One on one semistructured interviews were carried out with twelve members trained as peer outreach volunteers. Interview transcripts were analysed using a consensual qualitative research approach. Outreach workers typically experienced peer outreach as a positive experience both for themselves and for the recipients. Most found the training and support provided to be appropriate and sufficient. Nonetheless, peer outreach workers did encounter difficulties and sometimes felt need for more training and support. The findings have implications for the development of future peer outreach programs. There is scope for enhanced training and/or supervision and a need for further research to investigate ways to optimise peer outreach.
\end{abstract}

\section{Keywords}

peer outreach, psychiatric disability, benefits, challenges, consumers

\section{Introduction}

The new recovery-based mental health system and the push towards consumer-oriented practice has led to a rapid increase in non-professional consumer-delivered services (Cook, Jonikas \& Razzano, 1995; Dixon, Krauss \& Lehman, 1994; Mead, Hilton \& Curtis, 2001; Mowbray, Moxley, Thrasher et al., 1996). Included in these services are the emerging models of peer support and outreach. Peer outreach differs from peer support in that it consists of a defined number of contacts with recipients rather than involving an ongoing support process (Clay, Schell, Corrigan $\&$ Ralph, 2005). There is an extensive body of literature promoting the interpersonal and intrapersonal benefits of peer support to peer providers (Armstrong, Korba \& Emard, 1995;
Hutchinson, Anthony, Ashcraft et al., 2006; Lieberman \& Gowdy, 1991; Mowbray, Moxley \& Collins, 1998; Salzer \& Shear, 2002; Solomon, 2004; Solomon \& Draine, 2001). However, there is a dearth of research specifically assessing the mode of peer outreach and the personal impact outreach provision has on the providers. It is important to discover whether peer providers receive similar benefits from carrying out minimal outreach visits as they do from providing ongoing support. This article endeavours to address this vacuum.

Peer support is a developing concept that a number of articles have attempted to define (Davidson, Chinman, Sells \& Rowe, 2006; Mead et al., 2001; Min, Whitecraft, Rothbard \& Salzer, 2007; Solomon, 2004). Solomon (2004)

Contact: $\quad$ Robert King, Associate Professor, Department of Psychiatry, The University of Queensland, St Lucia, Queensland, Australia r.king1@uq.edu.au

Citation: $\quad$ King, R., Lloyd, C., Clune, A., \& Allan, R. (2009). The experience of being a peer outreach volunteer: Benefits and challenges. Australian e-Journal for the Advancement of Mental Health, 8(1), www.auseinet.com/journal/ vol8iss 1/king.pdf

Published by: Australian Network for Promotion, Prevention and Early Intervention for Mental Health (Auseinet) www.auseinet.com/journal Received 18 August 2008; Revised 23 April 2009; Accepted 23 April 2009 
proposed peer support to be mutually provided 'social emotional support,' which often occurs alongside active or 'instrumental support' ( $p$. 393). Furthermore, peer support has been described as a 'system of giving and receiving help founded on key principles of respect, shared responsibility, and mutual agreement of what is helpful' (Mead et al., 2001, p.135). Individuals can freely connect with others who they feel are similar to them away from the conventional consumer/professional relationship. Davidson et al. (2006), however, have classed peer support as being quite distinct from both mutual support groups and peer run programs wherein the relationship between the support provider and recipient is one-directional rather than reciprocal. Despite these differences of opinion, one common element is that peer support is provided by people who have experienced a psychiatric disability firsthand to persons with a psychiatric disability, who are not as far along in their own recovery (Davidson et al., 2006; Min et al., 2007; Paulson, Herinckx, Demmler et al., 1999). It is also widely accepted that peer support is based on the premise that individuals who have faced and overcome great challenges can offer assistance, advice, hope, encouragement and perhaps act as role models to others in similar circumstances (Davidson et al., 2006, p. 443).

It is important to note that peer outreach differs from peer support in that it comprises a defined number of outreach contacts which aim to provide the recipient with information on available community services and supports. Peer outreach has existed in its own right and has been widely implemented in other areas, such as HIV prevention education among drug users, homeless youths and the gay community (Latkin, Sherman \& Knowlton, 2003; Podschun, 1993). In the arena of mental health practice, peer outreach is integrated into the peer support process. Indeed peer outreach does not stand alone and always seems to be partied with some manner of ongoing support. For example, Clubhouses, which are non-governmental organisations that provide ongoing peer support, will also supply outreach to retain existing members (Clay et al., 2005; Holter, Mowbray, Bellamy et al., 2004; Mowbray, Lewandowski, Holter \& Bybee, 2006).
The literature widely acknowledges the multiple benefits gained by people who carry out peer support (Armstrong et al., 1995; Corrigan, 2006; Hutchinson et al., 2006; Mowbray et al., 1998; Salzer \& Shear, 2002). Indeed, positive changes in self-worth and confidence, coping skills, a sense of empowerment and communication skills are experienced by these individuals (Corrigan, 2006; Mowbray et al., 1998; Weissman, Cowell, Kushner et al., 2005). The 'helper-therapy principle' lies at the heart of peer provided services and proposes that an individual derives personal benefits from helping others (Riessman, 1965). These benefits include increased interpersonal capability, a feeling of receiving as much as is given, individual learning and a greater sense of self (Riessman, 1965).

A number of studies have also documented the challenges involved in providing peer support (Mowbray et al., 1996, 1998; Paulson et al., 1999). Problems identified by peer support providers have included difficult behaviour from recipients, feeling inadequate compared to other healthcare professionals, and personally taking on board recipients' issues (Mowbray et al., 1996, 1998). Furthermore, boundary issues are commonly experienced by peer support workers due to their blurred role of friend and of service provider (Mowbray et al., 2006; Paulson et al., 1999).

This study aimed to identify benefits and challenges of outreach provision from the perspective of a group of voluntary outreach workers from Stepping Stone Clubhouse in Brisbane, Australia. It was expected that peer outreach would hold similar benefits for the peer volunteer as peer support, despite the more fleeting nature of the outreach contacts. The challenges faced by peer outreach providers were hypothesised to be less severe than those experienced by people providing peer support, due to the reduced contact time and limited direct involvement with recipients. Furthermore, this study aimed to assess how peer volunteers viewed their work as benefiting the recipients. The authors also hoped to discover methods of assisting peer volunteers more efficiently with their outreach work by eliciting their views on the peer outreach program as a whole, and their suggestions for project improvements. 


\section{Method}

\section{Overview}

This was a qualitative study that explored the experience of peer outreach workers. Participants were members of Stepping Stone Clubhouse providing peer outreach in a larger study investigating the effectiveness of peer outreach with people awaiting discharge from acute inpatient psychiatric care. Data were collected by two masters level occupational therapy students (AC and RA) who were trained and supervised by the senior researchers (RK and CL). Data collection used semi-structured interviews specifically designed for the project. Data were analysed using the Consensual Qualitative Research (CQR) methodology (Hill, Thompson, Hess et al., 2005; Hill, Thompson \& Williams, 1997). Broad topic areas (domains) are determined, and within each domain, core ideas are derived from all data in every interview. Finally, themes are identified from the data in each core idea within each domain. The primary research team uses a consensus approach to reach agreement on domain, core ideas and themes. One to two auditors check the consensus judgements for accuracy and the primary research team continually refers back to the raw data to ensure accuracy of results and conclusions (Hill et al., 1997, 2005).

\section{Participants}

To be included in the study, participants had to meet the following criteria: minimum of one month membership of Stepping Stone Clubhouse; completion of a training program in provision of peer outreach; and, provision of a minimum of three peer outreach contacts. Twelve people ( 7 female, 5 male) met these criteria and agreed to participate in the study. Table 1 outlines demographic information for the participants.

\section{Intervention}

The Peer Outreach Program was a collaboration between the Princess Alexandra Hospital, the Stepping Stone Clubhouse and The University of Queensland. Under the program, clubhouse members, who were people with a personal history of severe mental illness, volunteered to undertake training and provide peer outreach to people awaiting discharge from acute psychiatric inpatient care at the Princess Alexandra Hospital.
Table 1. Participant demographic information

\begin{tabular}{cccrrrr}
\hline & & & & \multicolumn{2}{c}{ N contacts } \\
\cline { 5 - 6 } Participant & Age & Gender & $\begin{array}{c}\text { Clubhouse } \\
\text { membership }\end{array}$ & Initial & $\begin{array}{r}\text { Follow- } \\
\text { up }\end{array}$ \\
\hline 1 & 28 & $\mathrm{~F}$ & $1.5 \mathrm{mos}$ & 6 & - \\
2 & 53 & $\mathrm{~F}$ & $2 \mathrm{yrs}$ & 3 & - \\
3 & 42 & $\mathrm{M}$ & $12.5 \mathrm{yrs}$ & 4 & - \\
4 & 32 & $\mathrm{~F}$ & $1 \mathrm{yr}$ & 20 & 20 \\
5 & 23 & $\mathrm{M}$ & $6 \mathrm{mos}$ & 4 & - \\
6 & 22 & $\mathrm{M}$ & $10 \mathrm{mos}$ & 6 & - \\
7 & 39 & $\mathrm{~F}$ & $2 \mathrm{yrs}$ & 5 & 3 \\
8 & 30 & $\mathrm{M}$ & $1 \mathrm{yr}$ & 5 & 3 \\
9 & 23 & $\mathrm{~F}$ & $2 \mathrm{yrs}$ & 4 & 1 \\
10 & 56 & $\mathrm{~F}$ & $10 \mathrm{yrs}$ & 4 & 4 \\
11 & 43 & $\mathrm{M}$ & $5 \mathrm{yrs}$ & 4 & 2 \\
12 & 59 & $\mathrm{~F}$ & $5 \mathrm{yrs}$ & 6 & 1 \\
\hline
\end{tabular}

The purpose of the outreach was to provide a link to peer supports and other community resources that might be helpful to the recipient after discharge. While the outreach included information about the Clubhouse and an invitation to visit, this was not the only focus and recipients were provided with information and links to a range of supports and resources.

Staff of the Stepping Stone Clubhouse undertook training of the outreach workers and coordination of the outreach visits. The training involved clarification of the purposes of the outreach visit, information about resources and other matters that might assist members to respond to questions from those they were outreaching, and role plays. The role plays were a central part of the training and involved members simulating outreach contacts with other members and receiving feedback from members and staff. While the training was coordinated by staff, members played an active role in the development of the training approach and in modifications of it as the program developed. A designated member of the clinical team at Princess Alexandra Hospital was responsible for liaison with visiting outreach workers who were usually accompanied by a staff member.

The outreach referred to in this paper had two components. Initial outreach involved a visit to the inpatient unit by members of Stepping Stone Clubhouse. Inpatients who had indicated to hospital staff that they were interested in receiving an outreach visit were engaged in an informal meeting process by two or three Clubhouse members, sometimes accompanied by 
a Clubhouse staff member. These meetings typically occurred with one inpatient at a time and lasted for 15-45 minutes. Where appropriate, outreach workers shared stories of their own experience of mental health care. Recipients were provided with information about the Stepping Stone Clubhouse and other community supports and were invited to visit for a 'tour' of the clubhouse after discharge. The second outreach component occurred after the outreach recipient had been discharged. Within two weeks of discharge, the outreach recipient was telephoned; those who had received an outreach visit as an inpatient were telephoned and offered support, advice and another opportunity to link up with the clubhouse. These calls were not always successful in making contact because phone numbers provided were not valid or the person could not be reached. Phone calls typically lasted 5-15 minutes.

\section{Instrument}

Consistent with the CQR approach outlined by Hill et al. (1997), interviews were semistructured using nine open-ended questions. The questions were designed by the research team, having reference to informal reports on the experience of peer outreach workers, provided by the peer outreach coordinator and peer outreach workers who were members of the committee overseeing the larger study investigating the effectiveness of peer outreach. They addressed three broad areas of interest in the study: the adequacy of training, supervision and support provided to the peer outreach workers; the response of people who were recipients of peer outreach contacts; and, the impact of the peer outreach experience on the peer outreach workers. The questions were as follows:

1. How well were you prepared for your outreach work; for example, how well did you understand the project and the work involved, how effective was your training?

2. How have patients responded to the outreach contacts, both in the hospital and at the follow-up after discharge?

3. What kinds of things do patients want to talk about during the contacts?

4. Are there any aspects of the outreach contacts that patients have disliked or felt uncomfortable about?
5. What aspects of the outreach experience have you personally found useful and worthwhile?

6. What specific skills have you developed as a result of your outreach work?

7. Are there any aspects of the outreach experience that you have found stressful or difficult?

8. What kinds of supports have you received to assist you with the outreach work?

9. Are there any other supports that would be helpful to you or assist you to do the outreach work more effectively?

\section{Procedure}

Ethical clearance for this project was obtained from the Ethics Committee at The University of Queensland and Princess Alexandra Hospital Ethics Committee, Brisbane, Australia. All participants gave informed consent prior to commencing the interview. One investigator conducted five interviews and the second investigator conducted seven interviews. Interviewers used the questions as a guide but were also free to follow up with clarifying questions or explore new or different ideas spontaneously provided by participants during the interview process. Interviews lasted approximately 40 minutes and were audio-taped using a digital voice recorder. The interviewers transcribed their recordings and returned them to participants for further comment or clarification. Four participants declined this opportunity, five participants made minor corrections or comments, and three participants returned their transcripts without change.

\section{Data analysis}

Following the CQR methodology (Hill et al, $1997,2005)$ a five step process was followed when analysing data:

1. Developing domains: Preliminary domains were identified by the research team after an initial review of the transcripts. The domains cluster information about similar topics and are derived from the raw data as well as the literature review. Domains were then investigated systematically within each transcript by two members of the team (AC and RA). Final domains were then determined after discussion by all four team members until a consensual decision was reached. 
2. Constructing core ideas: The two members of the research team (AC and $\mathrm{RA}$ ) independently organised the raw data within each interview for each domain into core ideas and then met with the larger team to discuss their findings. Final core ideas were determined by the team through a consensual process.

3. Cross analysis: In the first phase of the cross analysis two members of the investigating team (AC and RA) worked together on 10 of the 12 transcripts to identify general, typical and variant themes. General themes are those present in all interviews, typical themes are those present in at least half of the interviews and variant themes are present in at least two transcripts but less than half. The four members of the investigating team then reviewed the allocation of category to themes to finalise the cross analysis.

4. Auditing: An auditor subsequently analysed the cross analysis, ensuring the core ideas and themes were representative of the raw data. The auditor specifically analysed the wording of core ideas and themes to ensure they captured the essence of the data. Feedback was provided to the research team during this process.
5. Stability check: This process involved analysing the two transcripts withheld from cross analysis, to determine whether changes were required to domains and core ideas. Analysis of these two transcripts did not identify further domains or categories; therefore, the original findings were considered to be stable.

\section{Results}

Transcript analysis yielded three domains: 'experience of the outreach program', 'provision of outreach' and 'recipient experience'. These domains, together with associated core ideas, themes and illustrative quotes are set out in Tables 2 to 4 .

\section{Domain 1: Experience of outreach program}

Two core ideas were identified in relation to the peer outreach program: experience of training and experience of supports available/utilised. Peer outreach volunteers' experience of the Program is detailed below in Table 2.

With respect to training and preparation, Table 2 shows that peer outreach providers typically drew on both their own personal life experiences

Table 2. Domain 1: Peer volunteers' experience of the outreach program

\begin{tabular}{|c|c|c|}
\hline Themes & Frequency & Illustrative quotes \\
\hline \multicolumn{3}{|c|}{ Core Idea 1: Experience of training } \\
\hline Found training beneficial & Typical & $\begin{array}{l}\text { 'We had training at Stepping Stone organised with Michael (staff member } \\
\text { who coordinated the project at the Clubhouse) and a group of other people } \\
\text { and that training gave us a good grounding into what we had to do'. } \\
\text { (Transcript } 7 \text { ) }\end{array}$ \\
\hline $\begin{array}{l}\text { Prepared using own past } \\
\text { experience / program resources }\end{array}$ & Typical & $\begin{array}{l}\text { 'I found it really easy to do because l've done a life coaching course } \\
\text { before, so it was just really easy to talk to people.' (Transcript 2) }\end{array}$ \\
\hline Inadequately prepared & Variant & $\begin{array}{l}\text { 'The first time I went in I wasn't quite sure what I had to do, I sort of had to } \\
\text { jump in the deep end. There was sort of a fuzzy area as to what exactly } \\
\text { was wanted.' (Transcript 2) }\end{array}$ \\
\hline \multicolumn{3}{|c|}{ Core Idea 2: Experience of supports available / utilised } \\
\hline $\begin{array}{l}\text { Fellow peer outreach volunteers } \\
\text { as supports }\end{array}$ & Typical & $\begin{array}{l}\text { 'We have regular meetings with other peer outreach workers... I talk about } \\
\text { how I feel and I find other peer outreach workers sometimes feel the same } \\
\text { way.' (Transcript 12) }\end{array}$ \\
\hline Program staff as supports & Typical & $\begin{array}{l}\text { 'If you do have any problems you can always get support from B and also } \\
\text { the staff members here. But Stepping Stone is providing support so, it's } \\
\text { good like that, so if you've got a problem you can get it sorted out, even on } \\
\text { the way back [in the car].' (Transcript } 4 \text { ) }\end{array}$ \\
\hline Need for more formal support & Variant & $\begin{array}{l}\text { 'Not a lot of support, that's why I suggest that maybe some debriefing, } \\
\text { afterwards would be good. The staff here at Clubhouse do as much as } \\
\text { they can but they're certainly not qualified in some ways to be dealing with } \\
\text { it, as in like counseling and stuff.' (Transcript } 3 \text { ) }\end{array}$ \\
\hline $\begin{array}{l}\text { Need for training in specific } \\
\text { skills }\end{array}$ & Variant & $\begin{array}{l}\text { 'I would like it if the support was a little bit more specific rather than them } \\
\text { just saying you're fabulous, you're doing great stuff. I would like to break it } \\
\text { down a little bit and talk specifically about improving conversational skills.' } \\
\text { (Transcript 12) }\end{array}$ \\
\hline
\end{tabular}


and the formal training provided in preparation for provision of peer outreach. They generally had a positive experience of the formal training and felt adequately prepared for their initial outreach contact. Two participants reported being inadequately prepared because they had not participated in the full training experience. They were able to manage the initial peer outreach because they were part of a group and were able to take a secondary role while learning how to do it through observation and interaction with others.

With respect to supports, Table 2 shows that peer outreach providers typically made use both of group supports - especially peer group debriefing sessions and individual support provided by hospital based or clubhouse based staff. While there was general satisfaction with

Table 3. Domain 2: Peer volunteers' experience of providing outreach

\begin{tabular}{|c|c|c|}
\hline Themes & Frequency & Illustrative quotes \\
\hline \multicolumn{3}{|c|}{ Core Idea 1: Perceived benefits to self } \\
\hline Skill improvement & General & $\begin{array}{l}\text { 'I think talking to people, conversational skills, organisational skills and my } \\
\text { confidence level has improved.' (Transcript 12) }\end{array}$ \\
\hline $\begin{array}{l}\text { Personal reward from } \\
\text { helping/giving back others }\end{array}$ & Typical & $\begin{array}{l}\text { 'It's helped me, the work I am doing; I feel like I am giving back to society. } \\
\text { It's throwing out a lifeline to a person; I find it uplifting.' (Transcript 10). }\end{array}$ \\
\hline Greater confidence and self-worth & Typical & $\begin{array}{l}\text { 'I've learnt a lot about myself and how valuable I am. I've also learnt that I } \\
\text { can help others in similar need. The peer outreach project has given me a } \\
\text { lot of confidence, a lot of self-esteem and value.' (Transcript 3) }\end{array}$ \\
\hline Ability to relate to people & Variant & $\begin{array}{l}\text { 'Also just being able to relate to other people, it made me feel great in it and } \\
\text { being able to speak to them and let them know that someone else has gone } \\
\text { through it too.' (Transcript 2) }\end{array}$ \\
\hline $\begin{array}{l}\text { Insight into own health and } \\
\text { recovery }\end{array}$ & Variant & $\begin{array}{l}\text { 'It's given me some insight into myself and where I was at, how far l've } \\
\text { come.' (Transcript 2) }\end{array}$ \\
\hline \multicolumn{3}{|c|}{ Core Idea 2: Challenging aspects of outreach work } \\
\hline Being reminded of past relapses & Typical & $\begin{array}{l}\text { 'The whole situation brings up all the past stuff for me, being in a psych } \\
\text { hospital and going through mental illness.' (Transcript 10) }\end{array}$ \\
\hline $\begin{array}{l}\text { Perceived lack of status and skill } \\
\text { compared to health care } \\
\text { professionals }\end{array}$ & Variant & $\begin{array}{l}\text { 'I used to find dealing with professionals hard, like I thought I wasn't as } \\
\text { good as them. Well, I think it was just something about the psych scene, } \\
\text { like the doctors were in charge and it went down like that.' (Transcript } 4 \text { ) }\end{array}$ \\
\hline $\begin{array}{l}\text { Taking the issues of outreach } \\
\text { recipients home }\end{array}$ & Variant & $\begin{array}{l}\text { 'Initially I was rehashing everything the clients said but } X \text { told me to let it go; } \\
\text { don't hang onto thoughts in my mind about the patients. That would be the } \\
\text { hardest thing I have to do.' (Transcript 10) }\end{array}$ \\
\hline $\begin{array}{l}\text { Talking with outreach recipients } \\
\text { who are very unwell / uninterested }\end{array}$ & Typical & $\begin{array}{l}\text { 'I had an instance with one person that made an appointment to see us and } \\
\text { that person really wasn't well and the stuff they were saying upset me.' } \\
\text { (Transcript } 5 \text { ) }\end{array}$ \\
\hline $\begin{array}{l}\text { Difficulty communicating / } \\
\text { managing own psychiatric } \\
\text { disability }\end{array}$ & Variant & $\begin{array}{l}\text { 'I found it all stressful and difficult to begin with, just the degree of sickness } \\
\text { amongst the clients and my own as well. I hadn't long come out of hospital } \\
\text { and I was suddenly thrust into this work.' (Transcript 12) }\end{array}$ \\
\hline \multicolumn{3}{|c|}{ Core idea 3: Experience of the post-discharge follow-up outreach } \\
\hline $\begin{array}{l}\text { Providing further contacts and } \\
\text { resources / further information on } \\
\text { Stepping Stone }\end{array}$ & General & $\begin{array}{l}\text { 'Not in the hospital, usually that comes later after discharge at the follow-up } \\
\text { calls [discussing contacts for employment]. Others talk about whether or } \\
\text { not they will come into Stepping Stone or whether we will be able to help } \\
\text { them.' (Transcript 12) }\end{array}$ \\
\hline $\begin{array}{l}\text { Outreach recipients are not } \\
\text { interested / unable to be contacted }\end{array}$ & General & $\begin{array}{l}\text { 'The two others I have attempted refused to talk to me so I just sent them } \\
\text { out a brochure on the peer outreach program and that was it. They were } \\
\text { less responsive on the phone, not particularly interested.' (Transcript 11) }\end{array}$ \\
\hline $\begin{array}{l}\text { Positive response from outreach } \\
\text { recipients }\end{array}$ & Variant & $\begin{array}{l}\text { 'Mostly it's been very positive. They have looked forward to hearing from us } \\
\text { and they've looked forward to coming to the clubhouse.' (Transcript } 3 \text { ) }\end{array}$ \\
\hline $\begin{array}{l}\text { Stressful experience for peer } \\
\text { outreach volunteer }\end{array}$ & Variant & 'You know it is stressful doing the cold calls.' (Transcript 11) \\
\hline
\end{tabular}

Note. Frequency adjusted for Domain 2, Core Idea 3 as only 7 peers conducted phone interviews. Typical = themes appeared in $6-7$ transcripts; general = themes appeared in 4-6 transcripts; and variant = themes appeared in only 2-4 of the transcripts. 
the level of support provided, two participants indicated need for additional support, specifically seeking more direct guidance as to how to provide peer support, as distinct from general affirmation concerning their role. In both cases, they thought this support might need to come from someone with greater expertise than a project team member.

\section{Domain 2: Peer volunteers' experience of providing outreach}

Three core ideas were identified in relation to the provision of peer outreach: perceived benefits to self, challenging aspects of outreach work and experience of the post-discharge follow-up outreach (see Table 3). It should be noted that only seven of the twelve participants had completed a follow-up phone call which means that five transcripts had no data in relation to the third core idea.

In relation to benefits to self, Table 3 shows that, typically, participants derived three types of benefit: positive feelings associated with the experience of helping others and contributing to the community; improved communication and interpersonal skills; and, generally increased confidence and self-esteem. In addition to these typical benefits, one participant expressed ideas about how contact with other people experiencing acute mental illness helped the outreach worker develop a better understanding of his or her own experience of mental illness.

In relation to the challenges of peer outreach, the only typical theme was that the experience activated memories of times when the outreach worker experienced acute illness. While this was not overwhelming, it was, for most outreach workers, a challenge that had to be overcome. The other challenges were specific to individuals and included feelings of inadequacy, difficult interpersonal experiences and taking home thoughts about the outreach contact.

In relation to the follow-up call, participants experienced considerable frustration in relation to either difficulties contacting people after they had been discharged from hospital or lack of interest when they were able to make contact. However, there was also general comment on the value of providing further information about resources and especially about the clubhouse, when they were able to make contact. Individuals reported both positive experiences when the recipient of a call was clearly appreciative and negative experiences associated with feelings of apprehension calling someone who was not known to the outreach worker.

Table 4. Domain 3: Peer volunteers' reports of recipients' experience of outreach

\begin{tabular}{|c|c|c|}
\hline Themes & Frequency & Illustrative quotes \\
\hline \multicolumn{3}{|c|}{ Core idea 1: Things recipients wanted to discuss } \\
\hline $\begin{array}{l}\text { Personal issues related to } \\
\text { family, employment, } \\
\text { accommodation }\end{array}$ & General & $\begin{array}{l}\text { 'A lot of it is family, they don't get along with their family or their family doesn't } \\
\text { understand. Occasionally it's housing, a lot of problems with housing because } \\
\text { of the housing situation.' (Transcript 3) }\end{array}$ \\
\hline $\begin{array}{l}\text { What will happen on their } \\
\text { discharge from hospital / } \\
\text { community supports available / } \\
\text { Stepping Stone }\end{array}$ & Typical & $\begin{array}{l}\text { 'What they want to do when they leave hospital, how they want to get work or } \\
\text { accommodation, and then we talk about how Stepping Stone would help them. } \\
\text { Some of the patients have talked about how they would like to join Stepping } \\
\text { Stone.' (Transcript 10) }\end{array}$ \\
\hline Their psychiatric disability & Variant & $\begin{array}{l}\text { 'They talked about struggling with life, their health including their mental health.' } \\
\text { (Transcript 11) }\end{array}$ \\
\hline \multicolumn{3}{|c|}{ Core idea 2: General response to outreach contact } \\
\hline $\begin{array}{l}\text { More accepting of peer } \\
\text { volunteer who understands } \\
\text { what they are going through }\end{array}$ & Typical & $\begin{array}{l}\text { 'Other times it's just having someone there to understand what they're going } \\
\text { through, their feelings and the frustration of having a mental illness, and just } \\
\text { having another person who can understand that.' (Transcript 3) }\end{array}$ \\
\hline $\begin{array}{l}\text { No interest, felt it was being } \\
\text { forced upon them }\end{array}$ & Typical & $\begin{array}{l}\text { 'If I just walked up and started talking about Stepping Stone straight off they've } \\
\text { shown that they're not interested because they've heard about it earlier and } \\
\text { they feel like it's being forced down their necks a bit.' (Transcript } 4 \text { ) }\end{array}$ \\
\hline $\begin{array}{l}\text { Consented to involvement, } \\
\text { therefore happy to talk }\end{array}$ & Variant & $\begin{array}{l}\text { 'That's the thing; the people that actually chose to be involved are quite happy } \\
\text { to talk; if they weren't they wouldn't be involved.' (Transcript } 8 \text { ) }\end{array}$ \\
\hline Too unwell to participate & Variant & $\begin{array}{l}\text { 'I really think that they are often not at the stage where they can comprehend } \\
\text { anything much at all. They are really in the throes of illness and their minds are } \\
\text { not focussed on what it is we are there to talk about.' (Transcript 12) }\end{array}$ \\
\hline
\end{tabular}




\section{Domain 3: Recipient experience}

Two core ideas were identified in relation to the recipients' experiences of the peer outreach contacts: things recipients wanted to discuss; and general response to outreach contact. Peer reports of recipients' experience of outreach are set out in Table 4.

In relation to what recipients discussed with the peer outreach worker, the most general topic was broad life challenges and difficulties in diverse areas such as family relationships and employment. Typically discussed were more immediate concerns about how the person would manage re-engagement with the community following discharge. Less frequently but sometimes discussed, were matters directly related to the person's illness.

In relation to the recipient's response to the outreach contact, there were two clear themes. One typical response was appreciation of contact from a peer who had been through a similar experience. However, another typical response was indifference or sometimes even negativity in relation to the contact, so that the outreach worker felt she or he was imposing on the person, even though the person had agreed to a contact. A variant on this theme was that the person was too acutely unwell to make use of the contact.

\section{Discussion}

The aim of this qualitative study was to understand the peer outreach experience from the perspective of the peer outreach worker. Of particular interest were the experiences outreach workers had of the training and supports provided within the program, the impact on the outreach worker of providing peer outreach, and their perceptions as to the impact outreach had on the recipient.

\section{Training and support}

The majority of peer volunteers found weekly training sessions beneficial in preparing them for their outreach work. Peers felt that the role playing scenarios were helpful, in conjunction with gaining information from peer volunteers with comparatively more experience. Outreach workers who missed these sessions and were inducted into the program on a 'learn as you go' basis reported feeling disadvantaged, at least at the beginning. More than half the peer volunteers interviewed indicated that they also drew from their past experiences for their outreach work. This is consistent with previous studies which found that knowledge gained from past experience was important in assisting peer providers to feel confident in their role and for problem-solving recipient's issues (Dixon, Hackman, \& Lehman, 1997; Solomon, 2004).

The findings from this study suggest that, after initial training, fellow peer outreach volunteers and program staff are the main supports. Peer volunteers frequently mentioned the benefit of having both another more experienced peer volunteer and a clubhouse staff member present during outreach contacts. The pairing of less experienced peers with those who were more experienced to provide extra support appears to be an effective aspect of the program design. This type of support is common within the Clubhouse model and may not be present to the same degree in outreach programs conducted outside of this clubhouse setting.

Although the majority of peer volunteers reported receiving adequate support, some commented on the need for more formal training oriented towards the acquisition of specific skills, such as communication techniques and strategies to deal with difficult behaviour. Hutchinson et al. (2006) stated that even those peer-run programs based on best practice commonly use informal training and support for their peer providers. The evidence from this study suggests that at least some peer outreach workers wanted clearer feedback, specifically highlighting their strengths as well as areas for improvement in their performance. Mowbray et al. (1998) point out that supervision of peers is often superficial and advice is not specific enough to assist peers with the issues that may arise. There is some evidence that this may also have applied in this study. It is possible the project staff, mindful of the mental health history of the outreach workers, exclusively focused on general positive and supportive feedback and overlooked a need for feedback more focused on improving role performance.

Overall, the findings in relation to training and support are consistent with previous research that outlines the importance of adequate training 
and supervision of volunteers to ensure favourable program outcomes for both the peer volunteers and the recipients (Armstrong et al., 1995; Hutchinson et al., 2006).

\section{Impact of outreach on the outreach worker}

The findings of this study appear to support the assumption that peer outreach would hold similar benefits for the peer outreach worker as has been reported in the literature in relation to peer support workers (Corrigan, 2006; Mowbray et al., 1998). Specifically, the outreach workers felt positive about engaging in a helping role, reported developing new communication skills and reported that the experience had a positive impact on their self-esteem and confidence. This suggests that the brief and relatively isolated contacts characteristic of peer outreach do not negatively impact the benefits to the peer outreach workers.

Contrary to our initial expectations, our findings suggest that peer outreach volunteers do face many of the challenges identified in the peer support literature. They encounter negativity or indifference from some recipients which challenges both their skills and their morale. They experience multiple reminders of times when they were themselves acutely unwell. Sometimes they feel inadequate in the role and sometimes they are unable to stop thinking about contacts with people. While they did not report the same difficulties with role boundaries experienced by peer support workers (Dixon et al., 1994; Mowbray et al., 1996), they did experience apprehension associated with making contact with people they do not know.

The challenges reported by peer outreach workers in this study are mostly consistent with the findings of a number of studies on the experience of peer support workers (Mead et al., 2001; Mowbray et al., 1996, 1998). Paulson et al. (1999) have also suggested that peer support workers may be especially vulnerable to the stress of delivering a service to persons with a psychiatric disability. Concerns expressed by participants in this study of a lack of status and skill compared to mental health professionals was also found in a study of peer support workers by Mowbray et al. (1998).

The two week post-discharge follow-up call presented particular difficulties. Whereas the initial contact involved a group contact in an inpatient hospital setting, the follow-up contact was by telephone and was conducted by a single outreach worker. This was a source of apprehension for some outreach workers and frustration for others The majority of peer outreach calls either failed to achieve contact (due to recipient relocation or incorrect telephone contact details supplied) or the outreach recipient was not interested in further contact. While there were positive experiences associated with the follow-up call, it was clearly a more difficult and frustrating experience than the initial outreach visit to the acute inpatient unit.

\section{Perceptions of impact on those receiving outreach}

Peer outreach workers typically reported that recipients were happy to discuss life challenges and difficulties with someone who had been through a similar experience and understood their situation. Many recipients welcomed information about community supports available to them on discharge and were pleased to receive information about the clubhouse. These findings are similar to those from research conducted on peer support workers who were found able to develop a working alliance, even with recipients quite disengaged from the traditional approaches to care (Davidson et al., 2006).

Perhaps surprisingly, given that this was a research study in which recipients consented to outreach prior to the contact, peer outreach workers reported that some recipients responded with indifference or negativity, as if the outreach was being imposed upon them. This could be attributable to instability of mood or thinking among some recipients such that their mental state and attitude changed between the time when they gave consent to the contact and the time when the outreach team arrived. As discussed above, the outreach workers had difficulty with the follow-up contact. In part this was because it was difficult to make contact but also because some recipients of a follow-up contact were unappreciative or not interested. Thus, whereas the experience of the initial outreach contact was generally positive because recipients were available and typically appreciative, the experience of the follow-up was mixed because while some recipients were 
pleased to hear from the outreach worker, others could not be contacted or did not welcome the call.

\section{Limitations}

There are three main limitations to this study. First, there were only 12 participants and caution must therefore be exercised before generalising results. However, the participants formed the majority of those who met the inclusion criteria, and are almost certainly representative of the larger cohort of peer outreach workers who participated in the larger study. The few outreach workers who met inclusion criteria but were not interviewed were unable to be contacted by the interviewers or had dropped out of the outreach project for varying reasons. A second limitation, also relevant to generalisability, is that the peer outreach program in this study had specific characteristics and caution should be exercised when generalising findings to other forms of peer outreach.

The third limitation, which is inherent in much qualitative research, is that all data are processed and interpreted by the research team and are therefore subject to any biases within that team. The CQR method manages this risk through robust discussion and cross checking at different levels between individual perceptions, dyadic perceptions and full team consensus. It also uses some quantitative methods in classification of themes as general, typical or variant. However, these processes, while widely accepted, still leave the researcher as an intermediator between the experience of the participant and the reported findings.

\section{Implications and recommendations}

This study was quite specific in that it considered a specialised peer outreach program developed by Stepping Stone Clubhouse. One of the distinctive features of the Clubhouse model is that staff and members work collaboratively on many tasks and staff were involved in some outreach contacts. However, it should be noted that staff played a secondary and background role in these contacts. Their role was primarily to assist with transport of members to the hospital and to provide support if and when it was required. The actual outreach contacts were peer to peer and not mediated by staff. We therefore think that the distinctive features of this study do not preclude the results from having application to the fine-tuning of the peer outreach program under study or from providing a foundation for the development of future peer outreach programs in a mental health setting. Of note was the volunteers' desire for more specialised training and support. It is recommended that future outreach programs address these issues and that further qualitative research be conducted to determine if the improvements help to limit or overcome the challenges peer volunteers face in their role.

It should be noted that this was an outreach project in which Clubhouse members had brief and limited contacts with inpatients during an admission and after discharge. It is a different model from peer support which involves more sustained and ongoing contact and the findings reported here are likely to be at best partly applicable to peer support programs.

\section{Conclusion}

The CQR methodology allowed for an intensive investigation into the experiences of peer outreach volunteers. The study revealed that peer outreach volunteers accrued a number of interpersonal and intrapersonal benefits from volunteering in the peer outreach program. Furthermore, peer outreach volunteers commented on areas for improvement within the program, that if put into practice could assist in the ongoing success of future peer outreach projects. Importantly the study identifies the benefits and challenges specific to providing outreach rather than peer support. In this way it makes an important contribution to the current but limited body of knowledge on peer outreach programs.

\section{Acknowledgements}

The authors wish to thank all individuals who participated in this study, as well as Michael Connor, the Peer Outreach Coordinator at Stepping Stone Clubhouse. This project was conducted while AC and RA were postgraduate entry masters students in the Division of Occupational Therapy, The University of Queensland.

\section{References}

Armstrong, M.L., Korba, A.M., \& Emard, R. (1995). Mutual benefit: The reciprocal relationship between consumer volunteers and the clients they serve. Psychiatric Rehabilitation Journal, 19, 45-49. 
Clay, S., Schell, B., Corrigan, P., \& Ralph, R. (Eds.). (2005). On Our Own, Together: Peer Programs for People with Mental Illness. Nashville, TN: Vanderbilt University Press.

Cook, J., Jonikas, J., \& Razzano, L. (1995). A randomized evaluation of consumer versus nonconsumer training of state mental health service providers. Community Mental Health Journal, 31, 229-238.

Corrigan, P.W. (2006). Impact of consumer-operated services on empowerment and recovery of people with psychiatric disabilities. Psychiatric Services, 57, 1493-1496.

Davidson, L., Chinman, M., Sells, D., \& Rowe, M. (2006). Peer support among adults with serious mental illness: A report from the field. Schizophrenia Bulletin, 32, 443-450.

Dixon, L., Hackman, A., \& Lehman, A. (1997). Consumer as staff in assertive community treatment programs. Administration and Policy in Mental Health, 25, 199-208.

Dixon, L., Krauss, N., \& Lehman, A. (1994). Consumers as service providers: The promise and the challenge. Community Mental Health Journal, 30, 615-625.

Hill, C.E., Thompson, B.J., Hess, S.A., Knox, S., Williams, E.N., \& Ladany, N. (2005). Consensual qualitative research: An update. Journal of Counseling Psychology, 52, 196-205.

Hill, C.E., Thompson, B.J., \& Williams, E.N. (1997). A guide to conducting consensual qualitative research. The Counseling Psychologist, 25, 517-572.

-Holter, C.M., Mowbray, C.T., Bellamy, C.D., MacFarlane, P., \& Dukarski, J. (2004). Critical ingredients of consumer run services: Results of a national survey. Community Mental Health Journal, 40, 47-64.

-Hutchinson, D.S., Anthony, W.A., Ashcraft, L., Johnson, E., Dunn, E.C., Lyass, A., \& Rogers, S. (2006). The personal and vocational impact of training and employing people with psychiatric disabilities as providers. Psychiatric Rehabilitation Journal, 29, 205-213.

Latkin, C., Sherman, S., \& Knowlton, A. (2003). HIV prevention among drug users: Outcome of a networkoriented peer outreach intervention. Health Psychology, 22, 332-339.

Lieberman, A. \& Gowdy, A. (1991). The mental health outreach project: A case study in self-help. Psychosocial Rehabilitation Journal, 14, 100-105.
Mead, S., Hilton, D., \& Curtis, L. (2001). Peer support: A theoretical perspective. Psychiatric Rehabilitation Journal, 21, 160-163.

-Min, S., Whitecraft, J., Rothbard, A., \& Salzer, M. (2007). Peer support for persons with co-occurring disorders and community tenure: A survival analysis. Psychiatric Rehabilitation Journal, 30, 207-213.

Mowbray, C.T., Lewandowski, L., Holter, M., \& Bybee, D. (2006). The clubhouse as an empowering setting. Health and Social Work, 31, 167-179.

Mowbray, C.T., Moxley, D.P., \& Collins, M.E. (1998). Consumers as mental health providers: Firstperson accounts of benefits and limitations. Journal of Behavioural Health Services and Research, 25, 397-411.

Mowbray, C.T., Moxley, D.P., Thrasher, S., Bybee, D., McCrohan, N., Harris, S., \& Clover, G. (1996). Consumers as community support providers: Issues created by role innovation. Community Mental Health Journal, 32, 47-67.

Paulson, R., Herinckx, H., Demmler, J., Clarke, G., Cutler, D., \& Birecree, E. (1999). Comparing practice patterns of consumer and non-consumer mental health service providers. Community Mental Health Journal, 35, 254-269.

Podschun, G. (1993). Teen Peer Outreach-Street Work Project: HIV prevention education for runaway and homeless youth. Public Health Reports, 108, 150155.

Riessman, F. (1965). The 'helper-therapy' principle. Social Work, 10, 27-32.

Salzer, M.S. \& Shear, S.L. (2002). Identifying consumer-provider benefits in evaluations of consumer-delivered services. Psychiatric Rehabilitation Journal, 25, 281-288.

Solomon, P. (2004). Peer support/peer provided services: Underlying processes, benefits, and critical ingredients. Psychiatric Rehabilitation Journal, 27, 392-400.

Solomon, P. \& Draine, J. (2001). The state of knowledge of the effectiveness of consumer provided services. Psychiatric Rehabilitation Journal, 25, 20 27.

-Weissman, E.M., Covell, N.H., Kushner, M., Irwin, J., \& Essock, S.M. (2005). Implementing peerassisted case management to help homeless veterans with mental illness transition to independent housing. Community Mental Health Journal, 41, 267-76. 